\title{
Toric IOL in Combined DMEK and Cataract Surgery
}

This article was published in the following Dove Press journal:

Clinical Ophthalmology

\author{
Bruno Lovaglio Cancado \\ Trindade (D) ${ }^{1-3}$ \\ Julia Costa Garcia $\mathbb{1 D}^{2}$ \\ Laila Rahme Nogueira ${ }^{2}$ \\ 'Cançado Trindade Eye Institute, Belo \\ Horizonte, Brazil; ${ }^{2}$ Medical Science \\ School of Medicine - FELUMA, Belo \\ Horizonte, Brazil; ${ }^{3}$ Cornea Department, \\ Medical Sciences University Hospital Eye \\ Institute, Belo Horizonte, Brazil
}

Introduction: Descemet membrane endothelial keratoplasty (DMEK) is the current gold standard surgical procedure to treat Fuchs endothelial keratoplasty. Cataract removal and intraocular lens (IOL) implantation can be safely combined with this corneal procedure. This paper presents a case series in which a toric intraocular lens (IOL) was used in combined DMEK and cataract surgery to correct corneal astigmatism.

Methods: Four eyes that had a toric IOL implanted in combined cataract and DMEK surgery were included.

Results: There was a reduction in manifest refractive cylinder and improvement in uncorrected and best-corrected vision in all cases.

Discussion: Surgeons may consider the use of toric IOLs in selected cases of combined DMEK and cataract surgery for Fuchs endothelial dystrophy.

Keywords: Descemet membrane endothelial keratoplasty, DMEK, Fuchs endothelial dystrophy, toric intraocular lens, astigmatism, triple procedure

\section{Introduction}

Descemet membrane endothelial keratoplasty (DMEK) has been recently considered as the best surgical treatment for Fuchs endothelial dystrophy (FED). ${ }^{1}$ DMEK allows a faster recovery, a better visual outcome and lower rates of graft rejection when compared to Descemet Stripping Automated Endothelial Keratoplasty (DSAEK).

When combining cataract surgery with endothelial keratoplasty, the anterior corneal surface remains more or less intact facilitating corneal power estimation. Nevertheless, DSAEK grafts can alter the posterior corneal profile altering total corneal power calculation. When using DMEK grafts, the posterior corneal surface is essentially restored to a normal shape resulting in a more predictable postoperative corneal power enabling more precise IOL power calculation.

DMEK triple surgery has been recently associated with the implantation of a toric intraocular lens (IOL), and even multifocal lenses. ${ }^{2}$ This is a paradigm shift in the way combined cataract surgery and corneal transplantation are performed. Preoperative corneal power and astigmatism measurement are critical when considering the use of toric or multifocal IOLs. Moreover, the lack of induced posterior corneal aberrations with DMEK may give surgeons the possibility to use premium implants in these combined procedures. ${ }^{3}$

Toric IOLs are designed to correct regular and symmetric corneal astigmatism at the time of cataract surgery. Many publications have shown their safety and effectiveness
Correspondence: Bruno Lovaglio

Cancado Trindade Rua Manaus, 595, São

Lucas, Belo Horizonte, MG, 30.150-350,

Brazil

Tel +55 3I 324I 5544

Email bruno.trindade@ioct.org
Clinical Ophthalmology 2021:15 |5||-15|6

$|5|$

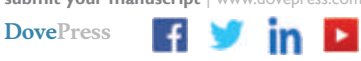

http://doi.org// 0.2147/OPTH.S293086 (c) (1) (5) 2021 Trindade et al. This work is published and licensed by Dove Medical Press Limited. The full terms of this license are available at https:///www.dovepress.com/terms. cC. work you hereby accept the Terms. Non-commercial uses of the work are permitted without any further permission from Dove Medical Press Limited, provided the work is properly attributed. For permission for commercial use of this work, please see paragraphs 4.2 and 5 of our Terms (https://www.dovepress.com/terms.php). 
to treat corneal astigmatism of up to 6D. These lenses can improve uncorrected vision in a significant number of patients. However, proper IOL alignment is mandatory and the rotation of even one degree may reduce the effective cylindrical correction of up to $3 \%{ }^{4}$ Thus, careful preoperative planning and meticulous surgical alignment are required to achieve an ideal outcome. This may be challenging in some more advanced forms of FED when the corneal edema may alter the corneal transparency and keratometry. ${ }^{5}$

This study presents cases of DMEK triple procedure in which a toric IOL was used. We describe our findings as well as compare them to the published results of other groups. We also discuss the required adjustments and considerations of this approach.

\section{Methods}

This is a retrospective study in which four eyes of three consecutive patients with mild to moderate Fuchs endothelial dystrophy that were submitted to DMEK triple surgery using a toric IOL were included. Surgeries were performed between August 2018 and November 2019 at a private clinic. The study followed the tenets of the Declaration of Helsinki and approval by the Institutional Review Board/Ethics Committee at FELUMA-MG was obtained (4.611.482). Written informed consent for publication of their details was obtained from all the patients.

All patients had a complete preoperative ophthalmological exam that included uncorrected and best-corrected distance and near visual acuity, subjective refraction, biomicroscopy, fundoscopy and tonometry. Central corneal thickness was assessed with a high-frequency ultrasound pachymetry (DGH-500 Pachete, DGH Technology). Corneal tomography was performed using a Scheimpflug corneal tomography (Pentacam HR, Oculus, Germany) and showed an orthogonal corneal astigmatism of over $1.5 \mathrm{D}$ in all patients. Ocular biometry was performed using the Lenstar 900 (Haag-Streit, Switzerland) and IOL power calculation was performed using the Barrett true-k formula (found online at www.apacrs.org). Central endothelial cell count was performed using a non-contact specular microscope (CEM-530, Nidek, Japan). All patients had an inferior peripheral iridotomy performed with the nd:YAG laser preoperatively to avoid pupillary block by the air bubble after surgery. After surgery, patients were assessed in their scheduled follow-up visits by a similar complete ophthalmic examination. A dilated exam was performed three months after surgery to assess proper meridional orientation of the IOL.
All patients were operated by the same experienced surgeon (BLCT). Donors were selected having 50 years old or more to facilitate unfolding with an endothelial cell count of over 2200 cells $/ \mathrm{mm}^{2}$. The DMEK graft was prepared at the time of surgery by the surgeon using a standard SCUBA technique and marked with an asymmetric "F" stamp to ensure proper graft orientation once inside the eye. ${ }^{6,7} \mathrm{Graft}$ diameter varied between 8 and $8.50 \mathrm{~mm}$. After a $2.2 \mathrm{~mm}$ temporal clear corneal incision was performed and the anterior chamber filled with cohesive ophthalmic viscosurgical device (OVD) a manual curvilinear capsulorhexis was performed aiming a diameter of 4.8-5.0mm. OVD use was limited to cohesive only (Healon, J\&J, Milpitas, USA) to facilitate aspiration before graft insertion, avoiding any interface deposits. Phacoemulsification was performed using the surgeons' preferred technique. After complete cortex removal, toric IOL implantation in the capsular bag (SN6ATx Alcon, Fort Worth, TX, USA) was followed by proper meridian alignment and meticulous aspiration of OVD under the IOL (Figure 1).

Descemetorhexis was then performed under cohesive OVD in the anterior chamber and a dilated pupil with the red reflex helping visualization of the membrane tear. The size of Descemet removal was $0.25 \mathrm{~mm}$ larger than the intended DMEK graft. Two sideports were created to facilitate graft maneuvering during unfolding. Acetylcholine $10 \mathrm{mg} / \mathrm{mL}$ was injected in the anterior chamber to promote miosis and OVD was completely removed using the I/A handpiece. The donor Descemet roll was stained with $0.1 \%$ trypan blue and inserted in the anterior chamber using a glass cartridge (Geuder, Germany). After the tissue was injected, it was completely opened and centralized in the cornea with the proper orientation verified by the asymmetric "F"-stamp. After that, a complete air fill was used to fixate the graft in place with intraocular

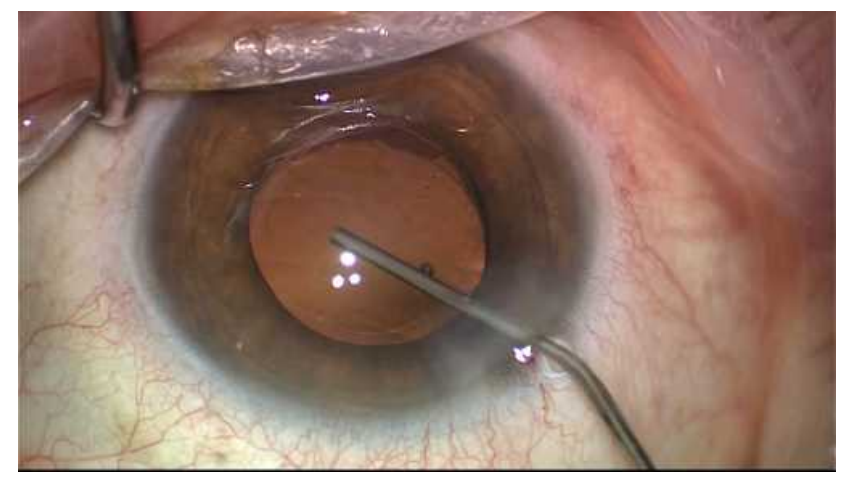

Figure I Toric IOL being aligned after implantation. 
pressure kept at high levels (around 40mmHg) for 10 minutes. After that, some air was released and BSS was injected in the anterior chamber to decrease the air bubble size to around $90 \%$. Surgery was then terminated and the patient was discharged home two hours later after confirmation that the air bubble level was above the patent inferior peripheral iridotomy.

Visual acuity was recorded in all visits and converted from decimal values to logarithm of the minimum angle of resolution (logMAR) using the following formula: ${ }^{8}$

$$
\log \mathrm{MAR}=-\log (\text { Decimal Acuity })
$$

Astigmatism was analyzed adhering to the terminology and graphical representations proposed by Abulafia et al. ${ }^{9}$

All continuous variables are reported using mean \pm standard deviation. Since this is a small series of cases, no statistical tests were performed.

\section{Results}

A total of 4 eyes of 3 patients (age 61 to 78 ) with mild to moderate Fuchs endothelial dystrophy with an orthogonal corneal astigmatism of over 1.5D was included in our study. Postoperative follow-up varied between 6 and 12 months. Mean preoperative uncorrected distance visual acuity (UCDVA) and near visual acuity (UCNVA) was LogMAR $0.73 \pm 0.19$ and $0.87 \pm 0.91$, respectively. Preoperative mean best-corrected distance visual acuity (BCDVA) was LogMAR $0.60 \pm 0.46$. Axial length varied between 22.33 and $22.99 \mathrm{~mm}$ (mean $22.56 \pm 0.29 \mathrm{~mm}$ ). Mean preoperative central corneal thickness (CCT) was $649 \pm 11 \mu \mathrm{m}$. Central endothelial cell density was uncountable in all patients preoperatively. Graft endothelial cell density was $2365 \pm 543$ cells $/ \mathrm{mm}^{2}$ as informed by the eye bank.

IOL model SN6ATx was used in all eyes. IOL power varied from 23.5 to $24.5 \mathrm{D}$ (mean $24.13 \pm 0.48 \mathrm{D}$ ). The IOL cylindrical power at the corneal plane ranged from 1.55 to $2.57 \mathrm{D}$ (mean $1.93 \pm 0.49 \mathrm{D})$. Preoperative corneal astigmatism centroid was 1.72 D@ $@ 2^{\circ} \pm 1.78$ D. Six months after surgery, postoperative mean UCDVA improved to LogMAR $0.12 \pm 0.04$, refractive astigmatism centroid at corneal plane was $0.09 \mathrm{D} @ 125^{\circ} \pm 0.53 \mathrm{D}$, and mean central endothelial cell count was $1604 \pm 236 \mathrm{cell} / \mathrm{mm}^{2}$.

Figure 2 shows the changes in astigmatism double angle plots before and after surgery.

Figure 3 shows corneal topography differential map before and after surgery of all 4 cases.
No intraoperative complications were noted in any surgery. No relevant IOL rotation was noted in any patient after surgery. In one eye, graft rebbuble was required and successfully performed 6 days after surgery due to significant graft detachment. All the other eyes had no relevant postoperative complications.

\section{Discussion}

The introduction of endothelial keratoplasty has changed the way we approach corneal endothelial diseases. With DMEK being a perfect anatomical replacement of the diseased endothelium, the refractive changes induced by the procedure are minimal or absent. This has improved the way we can combine this surgery with cataract extraction. Since the cornea after transplantation behaves almost like a normal cornea, premium IOLs can be considered even in combined surgeries. Toric IOLs have been increasingly considered as a choice of implant for their ability to bring formidable visual acuity in the presence of astigmatism and they can be potentially used in this setting. This is a significant change in the way we approach these patients.

The combined DMEK and cataract surgery with IOL implantation (triple procedure) has already proved to be an advantageous procedure, promoting a faster visual recovery, decreasing risks of graft rejection and reducing risks of additional endothelial damage. ${ }^{6}$

We report four cases of DMEK triple procedure in which a toric IOL was used. In all cases, there was a significant improvement in vision in all patients after surgery. The reduction shown in postoperative refractive astigmatism centroid value shows that this approach is valid. However, results may be worse than the ones using a toric IOL in a standard cataract surgery. IOL power calculation was performed using the Barrett true$\mathrm{K}$ formula (available online at www.apacrs.org) aiming for a slight myopic error ( $-0.50 \mathrm{D} \mathrm{sph})$.

The fact that, in all cases, we operated on less severe forms of FED might have contributed to the good results achieved. In initial stages of FED or in cases in which data preceding stromal edema is available, the IOL power calculation can be more reliably performed. Our series shows slightly better results than the ones published by Yokogawa et $\mathrm{al}^{2}$ with all patients achieving 20/30 uncorrected vision or better, 6 months after surgery. Hayashi et al have shown inferior optical corneal quality after DMEK with higher higher-order aberrations that may be caused by relative graft decentration although, in this study, most of the patients had pseudophakic bullous keratopathy rather the FED. ${ }^{10}$ 

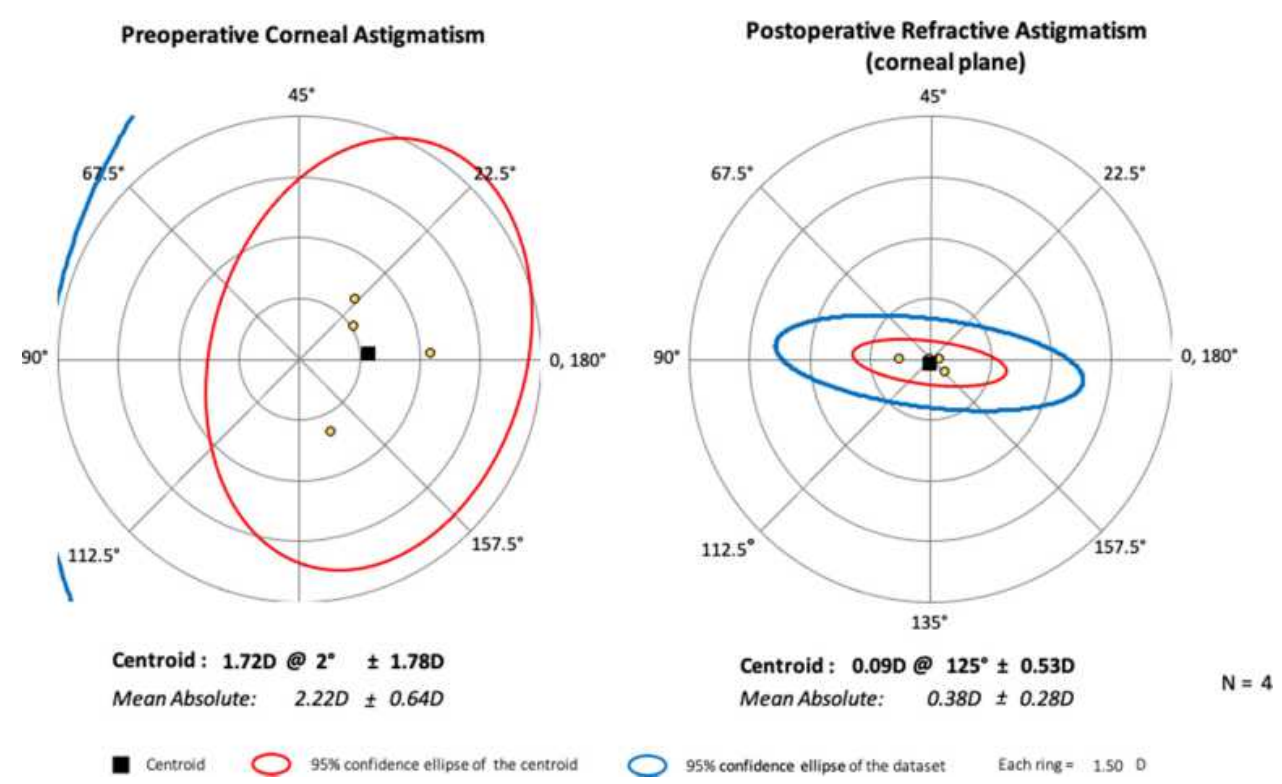

Figure 2 Astigmatism change after surgery.
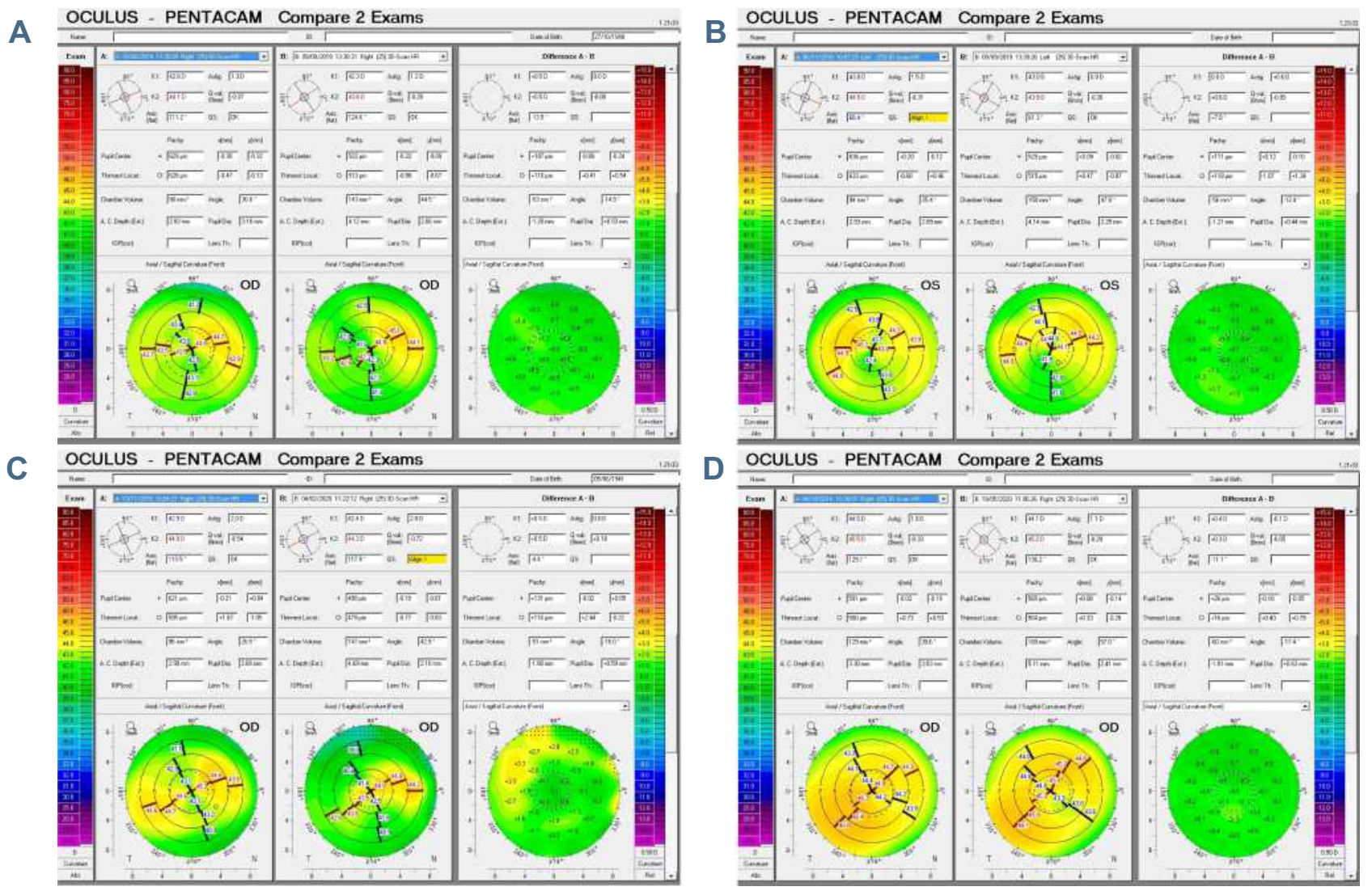

Figure 3 (A-D) Corneal topography differential map between before and after surgery of all 4 cases. Note the minimal change in the anterior astigmatism magnitude and orientation.

Changes in corneal astigmatism and total corneal power after DMEK for FED have been shown to be minimal. ${ }^{1}$ However, these changes can be more pronounced in cases of long- standing disease. A thicker preoperative cornea is expected to have a higher hyperopic change after the procedure. ${ }^{11}$ Additionally, there may be some subepithelial fibrosis in 
these long-standing cases responsible for some irregular astigmatism. Moreover, Shajari et al have shown that in patients with a higher difference in astigmatism between the 3 and $5 \mathrm{~mm}$ zones may have a decrease of this astigmatism after DMEK and this should be taken into consideration in cases of triple surgeries. ${ }^{12}$

Toric IOL rotation may be a concern when combining cataract with DMEK surgery since anterior chamber shallowing and tapping maneuvers might cause lens misalignment. In this small series, no significant IOL rotation was noted in any patient and we believe that the combination of thorough OVD removal behind the implant together with the tackiness of the lens material prevented any shift in the meridional orientation of the lens. ${ }^{13}$

Even though DMEK allows an excellent refractive result predictability, particularly when compared to the penetrating keratoplasty (PK) and DSAEK techniques, ${ }^{14}$ it is assumed that there can be changes in corneal refractive power after this procedure.

An overall reduction of total corneal power after DMEK has been reported. ${ }^{15}$ Arnalich-Montiel et al found that 46 eyes that underwent DMEK had their mean central keratometry almost $1 \mathrm{D}$ flatter than controls. ${ }^{5}$

These changes are due to corneal thinning and changes in anterior and posterior corneal surfaces which can lead to a hyperopic shift. As mentioned, it was found that more decompensated corneas are expected to have a more intense hyperopic shift after DMEK, which can be expected in individuals with more advanced stages of the disease. ${ }^{16}$ This way, eventual changes in the Gulstrand ratio must be considered in order to compensate for the corneal power change during IOL power calculation especially in cases in which a premium IOL is being planned.

On the other hand, Gupta et al reported that 47 eyes with FED that had at least $1.0 \mathrm{D}$ of anterior corneal astigmatism who underwent DMEK or triple DMEK procedure showed no significant difference in the magnitude of anterior astigmatism before and after the procedure. ${ }^{17}$ There is also a concern about modification of the orientation of the posterior corneal astigmatism after DMEK; however, the change of its magnitude and orientation may or may not be significant. ${ }^{18}$

IOL power calculation can be challenging, notably when cataract surgery is combined with any corneal procedure. ${ }^{19}$ This is especially critical with premium IOLs that have a lower tolerance to residual refractive errors. Even small amounts of residual spherical and/or cylindrical errors may compromise vision when a premium IOL is used. When considering these lenses in combined corneal surgeries, the patient must be informed about the unpredictability of IOL power calculation and possible need to further postoperative adjustments.

In this study, we demonstrated that in cases of mild to moderate FED associated with corneal astigmatism, astigmatism-correcting IOLs are an option in cataract surgery combined with DMEK. This is a paradigm shift in the way we plan for these combined surgeries. Despite several factors involved in predicting changes in corneal power and astigmatism after DMEK, it is possible to obtain a satisfactory refractive result in these cases given that the preoperative corneal measurements are reliable and the data are reproducible.

The relative small number of patients in this series prevents us to further assess the safety and efficacy of this approach and further studies are still required to validate the use of these implants in this setting.

\section{Conclusion}

The use of toric IOL in combined cataract and DMEK surgery may provide good uncorrected visual acuity and reduced postoperative refractive astigmatism in patients with Fuchs endothelial corneal dystrophy. Postoperative corneal astigmatism may not be as predictable as in patients undergoing cataract surgery alone.

\section{Disclosure}

The authors report no conflicts of interest in this work.

\section{References}

1. Yokogawa H, Sanchez PJ, Mayko ZM, et al. Corneal astigmatism stability in descemet membrane endothelial keratoplasty for fuchs corneal dystrophy. Cornea. 2016;35(7):932-937. doi:10.1097/ ICO.0000000000000882

2. Yokogawa H, Sanchez PJ, Mayko ZM, et al. Astigmatism correction with toric intraocular lenses in descemet membrane endothelial keratoplasty triple procedures. Cornea. 2017;36(3):269-274. doi:10.1097/ ICO.0000000000001124

3. Dunker SL, Dickman MM, Wisse RPL, et al. Descemet membrane endothelial keratoplasty versus ultrathin descemet stripping automated endothelial keratoplasty: a multicenter randomized controlled clinical trial. Ophthalmology. 2020;127(9):1152-1159. doi:10.1016/j. ophtha.2020.02.029

4. Potvin R, Kramer BA, Hardten DR, Berdahl JP. Toric intraocular lens orientation and residual refractive astigmatism: an analysis. Clin Ophthalmol. 2016;10:1829-1836. doi:10.2147/OPTH.S114118

5. Arnalich-Montiel F, Mingo-Botin D, Diaz-Montealegre A. Keratometric, pachymetric, and surface elevation characterization of corneas with fuchs endothelial corneal dystrophy treated with DMEK. Cornea. 2019;38(5):535-541. doi:10.1097/ICO.0000000000001875

6. Chaurasia S, Price FW Jr, Gunderson L, Price MO. Descemet's membrane endothelial keratoplasty: clinical results of single versus triple procedures (combined with cataract surgery). Ophthalmology. 2014;121(2):454-458. doi:10.1016/j.ophtha.2013.09.032 
7. Veldman PB, Dye PK, Holiman JD, et al. Stamping an $\mathrm{S}$ on DMEK donor tissue to prevent upside-down grafts: laboratory validation and detailed preparation technique description. Cornea. 2015;34(9):1175-1178. doi:10.1097/ICO.000000000 0000522

8. Holladay JT. Proper method for calculating average visual acuity. J Refract Surg. 1997;13(4):388-391.

9. Abulafia A, Koch DD, Holladay JT, et al. Pursuing perfection in intraocular lens calculations: IV. Rethinking astigmatism analysis for intraocular lens-based surgery: suggested terminology, analysis, and standards for outcome reports. J Cataract Refract Surg. 2018;44 (10):1169-1174. doi:10.1016/j.jcrs.2018.07.027

10. Hayashi T, Kobayashi A, Takahashi H, et al. Optical characteristics after descemet membrane endothelial keratoplasty: 1-year results. PLoS One. 2020;15(10):e0240458. doi:10.1371/journal.pone.0240458

11. Alnawaiseh M, Rosentreter A, Eter N, Zumhagen L. Changes in corneal refractive power for patients with fuchs endothelial dystrophy after DMEK. Cornea. 2016;35(8):1073-1077. doi:10.1097/ICO.00000000 00000842

12. Shajari M, Kolb CM, Mayer WJ, et al. Characteristics of preoperative and postoperative astigmatism in patients having descemet membrane endothelial keratoplasty. J Cataract Refract Surg. 2019;45 (7):1001-1006. doi:10.1016/j.jcrs.2019.02.002

13. Caporossi A, Casprini F, Tosi GM, Baiocchi S. Preliminary results of cataract extraction with implantation of a single-piece AcrySof intraocular lens. J Cataract Refract Surg. 2002;28(4):652-655. doi:10.1016/S0886-3350(01)01121-X
14. Woo JH, Ang M, Htoon HM, Tan D. Descemet membrane endothelial keratoplasty versus descemet stripping automated endothelial keratoplasty and penetrating keratoplasty. $\mathrm{Am} J$ Ophthalmol. 2019;207:288-303. doi:10.1016/j.ajo.2019.06.012

15. Kwon RO, Price MO, Price FW Jr, et al. Pentacam characterization of corneas with fuchs dystrophy treated with descemet membrane endothelial keratoplasty. J Refract Surg. 2010;26(12):972-979. doi:10.3928/ 1081597X-20100212-08

16. Price MO, Giebel AW, Fairchild KM, Price FW Jr. Descemet's membrane endothelial keratoplasty: prospective multicenter study of visual and refractive outcomes and endothelial survival. Ophthalmology. 2009;116(12):2361-2368. doi:10.1016/j.ophtha.2009.07.010

17. Gupta R, Kinderyte R, Jacobs DS, Jurkunas UV. Elimination of anterior corneal steepening with descemet membrane endothelial keratoplasty in a patient with fuchs dystrophy and keratoconus: implications for IOL calculation. Cornea. 2017;36(10):1260-1262. doi:10.1097/ICO.000000000001309

18. Alnawaiseh M, Zumhagen L, Rosentreter A, Eter N. Changes in anterior, posterior, and total corneal astigmatism after descemet membrane endothelial keratoplasty. $J$ Ophthalmol. 2017;2017:4068963. doi: $10.1155 / 2017 / 4068963$

19. Ham L, Dapena I, Moutsouris K, et al. Refractive change and stability after descemet membrane endothelial keratoplasty. Effect of corneal dehydration-induced hyperopic shift on intraocular lens power calculation. J Cataract Refract Surg. 2011;37 (8):1455-1464. doi:10.1016/j.jcrs.2011.02.033
Clinical Ophthalmology

\section{Publish your work in this journal}

Clinical Ophthalmology is an international, peer-reviewed journal covering all subspecialties within ophthalmology. Key topics include: Optometry; Visual science; Pharmacology and drug therapy in eye diseases; Basic Sciences; Primary and Secondary eye care; Patient Safety and Quality of Care Improvements. This journal is indexed on PubMed

\section{Dovepress}

Central and CAS, and is the official journal of The Society of Clinical Ophthalmology (SCO). The manuscript management system is completely online and includes a very quick and fair peer-review system, which is all easy to use. Visit http://www.dovepress.com/ testimonials.php to read real quotes from published authors. 